Article

\title{
Biophilic Cities Are Sustainable, Resilient Cities
}

\section{Timothy Beatley ${ }^{1}$ and Peter Newman ${ }^{2, *}$}

1 Department of Urban and Environmental Planning, University of Virginia, Charlottesville, VA 22904, USA; E-Mail: tb6d@cms.mail.virginia.edu

2 Curtin University Sustainability Policy (CUSP) Institute, Curtin University, Fremantle, WA 6160, Australia

* Author to whom correspondence should be addressed; E-Mail: p.newman@curtin.edu.au; Tel.: +61-8-9266-9032; Fax: +61-8-9266-9031.

Received: 5 June 2013; in revised form: 12 July 2013 / Accepted: 16 July 2013 /

Published: 5 August 2013

\begin{abstract}
There is a growing recognition of the need for daily contact with nature, to live happy, productive, meaningful lives. Recent attention to biophilic design among architects and designers acknowledges this power of nature. However, in an increasingly urban planet, more attention needs to be aimed at the urban scales, at planning for and moving towards what the authors call "biophilic cities". Biophilic cities are cities that provide close and daily contact with nature, nearby nature, but also seek to foster an awareness of and caring for this nature. Biophilic cities, it is argued here, are also sustainable and resilient cities. Achieving the conditions of a biophilic city will go far in helping to foster social and landscape resilience, in the face of climate change, natural disasters and economic uncertainty and various other shocks that cities will face in the future. The paper identifies key pathways by which biophilic urbanism enhances resilience, and while some are well-established relationships, others are more tentative and suggest future research and testing.
\end{abstract}

Keywords: biophilic cities; sustainable cities; resilient cities

\section{Introduction: The Emergence of a Biophilic Perspective on Cities}

There is increasing interest on the part of architects, planners and urban designers in biophilic design and much new writing and literature appearing in the last several years. Biophilic design holds that good design, at the building, site, city and regional scale, must include nature and natural elements. It is based especially on the concept of biophilia, popularized by Harvard myrmecologist and 
sociobiologist E.O. Wilson. Wilson argues that humans have co-evolved with nature and that we carry with us our ancient brains and our need to connect with and affiliate with nature, to be happy and healthy. Wilson defines biophilia as "the innately emotional affiliation of human beings to other living organisms. Innate means hereditary and hence part of ultimate human nature". To Wilson, biophilia is really a "complex of learning rules" developed over thousands of years of evolution and human-environment interaction [1-3].

And there is now a growing body of evidence of the positive physical and mental health benefits associated with greenery and green elements in living and work environments. Research at the building scale shows strong positive relationships between the presence of natural daylight, fresh air and greenery, with increases in worker happiness and productivity [4]. Similar studies show the positive power of schools that incorporate natural daylight and other green elements, to raise test scores of the students [5]. Considerable evidence and research, dating to the 1980's, has suggested the healing and recuperative power of nature in hospitals and health care facilities (including Ulrich's [6] classic study showing recovery from gall bladder surgery is significantly enhanced by views of nature). Evidence of the power of the green qualities and features is also emerging at neighborhood community scales. Green neighborhoods and more natural living environments have been associated with reductions in stress and increased levels physical and mental health [7-11]. An important study in The Lancet concludes that populations with greater exposure to green space experience lower mortality and that green space exposure can help reduce health inequalities [12]. The presence of nature, moreover, is associated with improvements in positive mood, cognitive performance and even creativity [13]. A recent pilot study using portable electroencephalography (EEG) caps further demonstrates the value of nature in reducing mental fatigue [14]. Nature has immense power to restore, heal and fascinate.

This emerging evidence and research has helped in turn to increase interest among urban designers and architects in designing buildings and facilities that enhance nature. While much energy and attention of late has been focused on biophilic design, this has largely assumed a focus on the building or site. Beatley [15] and others argue that while integrating green and natural elements into building design is critical, there is much value in fact in getting people out of buildings and to thinking more holistically about the natural qualities and conditions of the larger urban environments in which these buildings sit.

Cities and urban environments contain a variety of ecological and green assets, from parks to trees to rivers and riparian habitats, and increasingly, efforts are being made to further enhance the green elements and features of these living and work environments. Daylighting urban streams (taking them out of underground pipes and returning them to the surface), installing trails, planting new trees and forests, community gardens, installing green walls and vertical gardens, are among the many ways in which cities and urban environments can become greener. Biophilic urbanism can and must happen at different scales, and Table 1 presents some examples of biophilic design interventions that are possible.

Increasingly cities have developed and are implementing a host of biophilic programs, policies and initiatives. Cities like Chicago and Portland have developed extensive incentives and subsidies for installation of green features, such as green rooftops. Furthermore, increasingly, green features, such as green rooftops, are mandated, as in Toronto, for roofs over a certain size. Some cities, such as Seattle, have established so-called Green Factor standards, mandating minimum green and landscaping elements for certain types of new development, and other cities, such as Chicago, Baltimore and 
Montreal, are encouraging the greening of alleyways and other otherwise grey spaces in the city. Many cities have established extensive treeing programs and set ambitious tree-planting goals, with the cities of New York, Los Angeles and Houston each setting the goal of a million new trees. Furthermore, many American cities, such as Chicago and San Francisco, have modified their planning and zoning codes to permit urban agriculture.

Table 1. Biophilic city design elements across scales. Modified from Girling and Kellett [16]; first appeared in Beatley [15].

\begin{tabular}{cc}
\hline Scales & Biophilic design elements \\
\hline Building & Green rooftops \\
& Sky gardens and green atria \\
Rooftop garden & Green walls \\
Daylit interior spaces & Green courtyards \\
Block & Clustered housing around green areas \\
& Native species yards and spaces \\
& Green streets \\
& Urban trees \\
Street & Low impact development (LID); \\
& Vegetated swales and skinny streets \\
& Edible landscaping \\
& High degree of permeability \\
& Stream daylighting, stream restoration \\
& Urban forests \\
Ecology parks \\
Community gardens
\end{tabular}

The physical environment of cities, then, represents an essential requisite for creating biophilic cities. However, the true extent to which a city and its residents can be said to be biophilic, will depend on many other things, including whether and the extent to which citizens avail themselves of this nearby nature and the amount of time residents actually spend out-of-doors. How much they know about and care about this nearby nature is also an important indicator. A biophilic city, moreover, is 
also a city in which residents are actively involved in experiencing nature-e.g., hiking, bird watching, sky-gazing, gardening, among many other activities. Furthermore, citizens in biophilic cities have abundant opportunities to be engaged in restoring and caring for the nature around them. Table 2 presents a more comprehensive listing of the key qualities, not just those of physical design, by which a biophilic city might be described or defined (for more detail, see Beatley [15]). It is important to recognize that biophilic cities are not simply green cities. The presence of abundant nature is a necessary, but not sufficient condition, and the "philic" is as important as the bio. In biophilic cities, residents are directly and actively engaged in learning about, enjoying and caring for the nature around them and have developed important emotional connections with this nature.

Table 2. Some important dimensions of biophilic cities (and some possible indicators thereof). Summarized from Beatley [15].

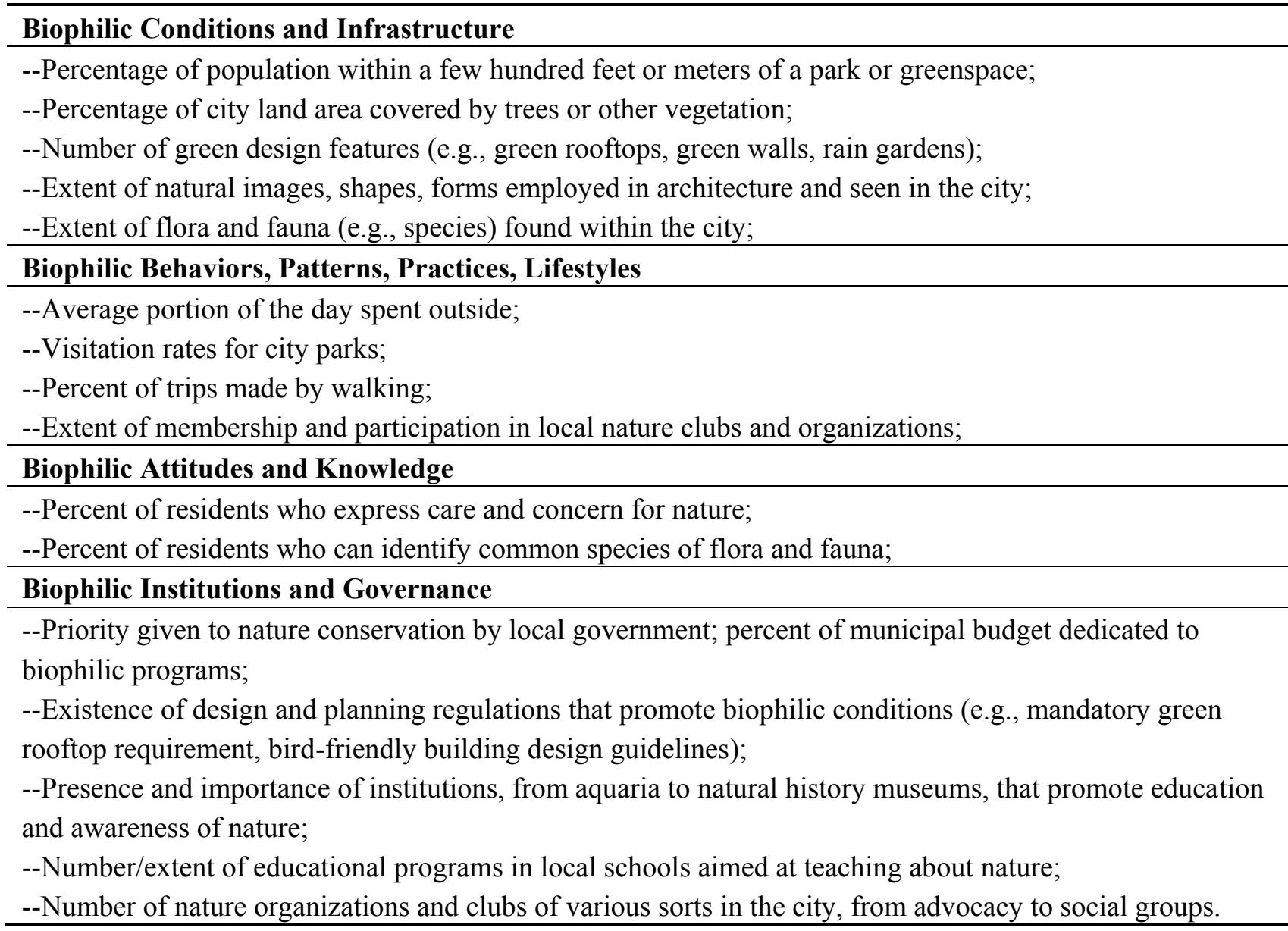

\section{Biophilic Cities and Urban Sustainability and Resilience}

Sustainability has emerged over the last two decades especially as an important goal and frame of reference for cities, and both authors have written extensively about what urban sustainability entails $[17,18]$. Sustainability is ideally understood as a holistic frame of reference for guiding city development and for helping cities to do many things at once: to reduce their ecological footprints and resource needs, to deepen connections to landscape and place and to enhance livability and quality of life while expanding economic opportunities for the least-advantaged, among others. 
Resilience has emerged as another important parallel concept and goal and an urban aspiration increasingly stated alongside (and sometimes replacing) sustainability. Given the impacts (current and potential) of global climate change, an increasingly volatile climate and the already serious range of disasters and hazards faced by cities around the world, global resource conflicts and constraints, long term decline in global oil supply and a global economic system that seems increasingly susceptible to vicissitudes and flux, resilience resonates well as a concept and goal, and we consider it a potent version or flavor of urban sustainability. What began with adaptation to disasters and hazards (many of us began speaking in terms of disaster-resistant and, later, disaster-resilient communities) has now broadened to discussions of resilient cities, that take into account the fuller range of potential shocks and stresses cities will likely face in the future, from water scarcity, rising food prices and higher summer temperatures [19]. Resilience has many meanings, of course, but at its core is the essential ability to successfully adapt to and respond to these shocks; the word derives from the Latin resiliere, meaning to jump back or rebound. Godschalk, while writing primarily from a natural hazards perspective, describes a resilient city as one that "would be capable of withstanding severe shock without either immediate chaos or permanent harm ... While they might bend from hazards forces, they would not break. Composed of networked social communities and lifeline systems, resilient cities would become stronger by adapting to and learning from disasters" [20-22]. Resilience does not imply a return to dysfunctional or unsustainable community conditions, but adaptation to dynamic social and ecological conditions in ways that protect and enhance quality of life, long term ecological productivity and public and personal health.

Resilience is not only a matter for cities and regions, of course, but has important implications for individuals and families. It is here often where the stresses, pressures and shocks of modern life will come to bear. Can individuals and families adapt and cope and in what ways? Will individuals and families be able to effectively and adequately adapt to the hotter conditions of urban neighborhoods, for instance, a likely result of climate change? Will they be able to respond effectively to future natural disaster events, as well as the impacts of future economic downturns (e.g., unemployment, rising food prices)? We are concerned here as well with the steps that can be taken to foster resilience at these levels: the ability of individuals and families to spring-back, to adapt and to take advantage of the opportunities to enhance their health and wellbeing.

It is the key premise of this paper that there are important relationships between biophilia or biophilic cities and urban sustainability and resilience and, more specifically, that the former helps to advance the latter. That is movement in the direction of making cities greener, more natural, more biophilic, will also help to make them more resilient. There are many pathways from biophilic design and urban biophilia to urban resilience, many ways in which the conditions of green and biophilic cities will also serve to make a city more resilient in the long run, ecologically, economically and socially. Some of these biophilic pathways are direct: as when investments in green infrastructure (say restoring wetlands or planting drought tolerant vegetation in cities) serves to yield resilience benefits and outcomes (e.g., reduced summer temperatures, reduced flooding from coastal storms). Other pathways are more indirect: as when green elements serve to stimulate or enhance beneficial and health-inducing behaviors, such as walking, that in turn serves to enhance the resilience of individuals and families to cope with future stresses. Figure 1 presents a very tentative conceptual diagram 
depicting the general flow of these pathways and suggesting some especially important pathways through which biophilic cities or biophilic urbanism, might positively influence urban resilience.

Figure 1. Biophilic pathways to urban resilience.

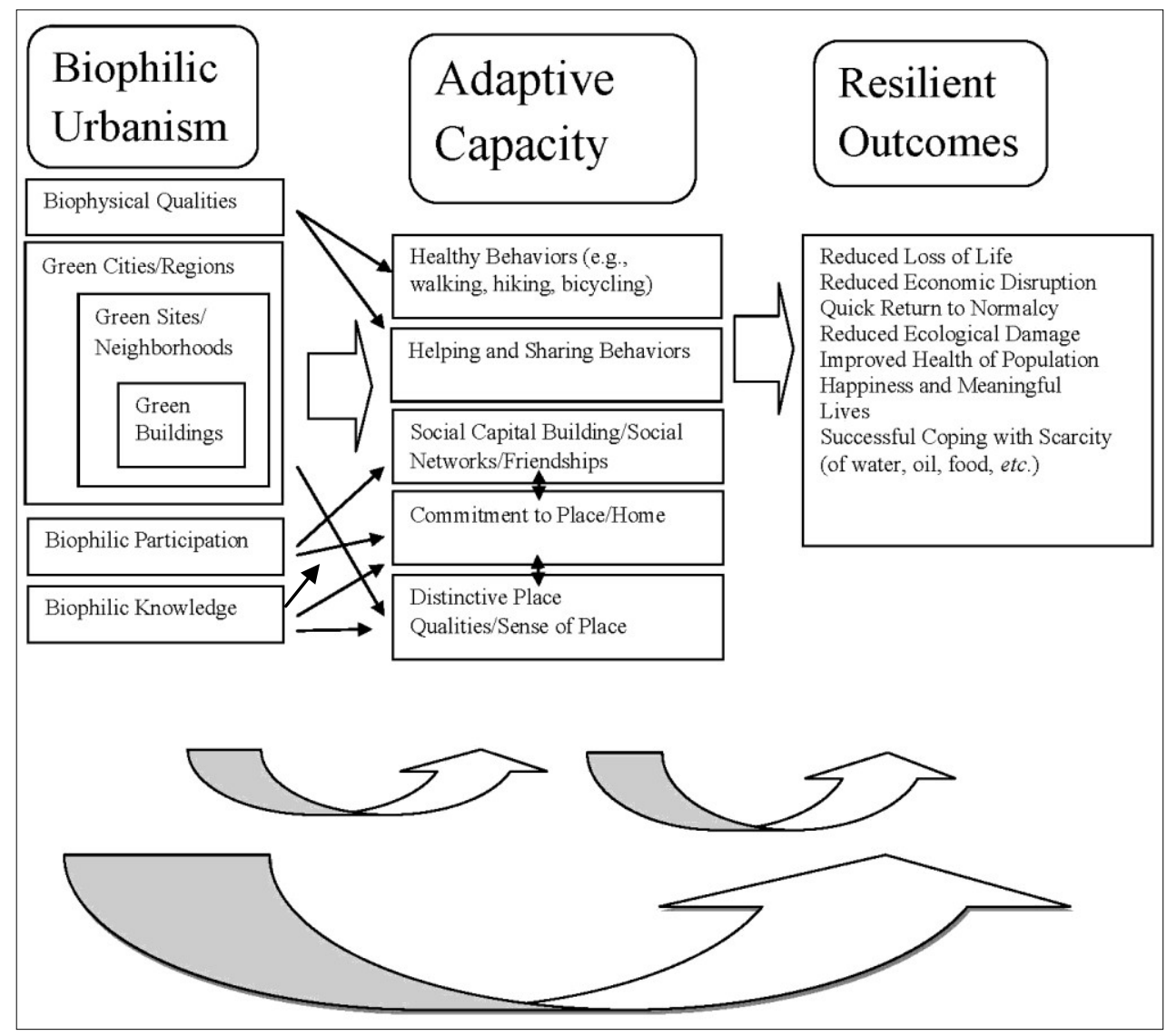

\section{Some Key Pathways from Biophilic Urbanism to Urban Resilience}

\subsection{Resilience through Urban Natural Systems}

There are a number of primary pathways, we believe, by which biophilic cities or biophilic urbanism will enhance or increase urban resilience. Some of these pathways and relationships have been well-researched and well-established. Others are more tentative and in need of additional work.

One of the clearest pathways is biophysical, the resilience benefits provided through the protection and enhancement of the natural systems and features in and around a city. We know that the green infrastructure of a city and region-rivers and riparian areas, floodplains and wetlands and large swaths of forested land - all provide essential services, that help cities and urban regions respond to and spring back from climatic and natural events. Cities with large natural wetland systems will be better able to absorb flood waters from hurricanes and storms, for instance. In New Orleans, for instance, vulnerability to storms and flooding has been significantly increased as a result of a long history of wetlands alterations. Costanza, Mitsch and Day [23] have argued compellingly for giving renewed importance to preserving and protecting an intact system of wetlands around New Orleans as a key strategy for long term resilience. These flood protection services carry a considerable economic value that must be recognized: "Had the original wetlands been intact and levees in better shape, a 
substantial portion of the US $\$ 100$ billion plus damages from this hurricane [Katrina] probably could have been avoided" [23]. In a more recent paper, Costanza and colleagues estimate that coastal wetlands provide some $\$ 23$ billion a year in hurricane protection benefits [24]. It has been estimated that every mile of protected forested cypress swamp in Louisiana, reduces flood surge heights by a foot or more. Protecting and restoring these larger ecological systems is a wise move in becoming more disaster-resilient.

Recent planning and policy initiatives around water and water supply for cities further suggest the direct resilience benefits of green infrastructure for enhancing water supply and water system resilience. The story of New York City's investment in the conservation and protection of its upper watersheds in the Catskills Mountains, is suggestive of the power of this framework. Here, the city has invested in acquisition and long term management of land (more than 70,000 acres protected through fee-simple or less-than-fee simple acquisition), a far more cost-effective method than the multi-billion dollar costs of water filtration plants and a model strongly supporting green or ecological infrastructure [25].

More recently, cities such as Denver, have entered into new long term restoration and conservation arrangements to make the city less susceptible to the water-supply impacts associated with wildfire and forest degradation in its source watersheds. The initiative called Forests to Faucets, more specifically, is an agreement between Denver Water and the U.S. Forest Service, an acknowledgement that the City of Denver's water supply has been seriously compromised in recent years as a result of wildfire-related sediment (the 2002 Hayman Fire, for instance, resulted in the deposition of more than 1 million cubic yards of sediment into one of the city's main water supply reservoirs). The agreement calls for a shared funding for a comprehensive program of interventions to enhance forest health and to address the problems of infestations from insects and threats of wildfire. These steps together will protect water supply delivery system for the city of Denver and will, as well, serve to make the forest upstream of the city more resilient in the face of these ecosystem changes. As the Denver water press release notes: "Restoration also will help the forests become more resistant to future insect and disease, reduce wildfire risks and maintain habitat for fish and wildlife. More resilient forests will also be more adaptive to the impacts of a changing climate" [26].

Cities with extensive tree canopy coverage provide many ecological benefits that will make cities more resilient-including moderation of air pollutants, cooling through evapo-transpiration and shading and reduction in urban flooding and runoff. Protection and restoration of urban streams and rivers will reduce vulnerability again to floods, provide important cooling benefits and help to moderate the weather and temperature changes predicted as a result of climate change (e.g., east coast American cities are predicted to have substantially higher summer highs by 2050). The cumulative impacts of green features, such as green rooftops and vertical gardens, can be significant indeed. In Toronto, the first North American city to now mandate installation of green rooftops for roofs over a certain size, estimates suggest that conversion of flat roofs to green rooftops would reduce urban temperatures by 1.5 degree Celsius or more [27].

Cities with more extensive networks of parks and greenspaces (though their design and configuration will matter) are also likely to fare better in the face of long term climate change. The City of Brisbane, Australia, a remarkably green city, aspires to create a connected network of natural areas, with topographic variation and diversity that will allow native biodiversity to adapt and shift as climate changes [28]. 
Trees and natural vegetation in cities and urban neighborhoods can help protect property and reduce damage from wind, rain and flooding. Some communities, such as Charleston County, SC, have developed programs for encouraging "hazard-resistant landscaping", planting native trees, such as live oaks, that tend to fare well in the face of high winds [29]. Working to make a neighborhood or community's landscape more resilient means finding ways to insert trees, landscaping, green rooftops and use of water sensitive urban design features, such as bio-swales and rain gardens.

Biophilic urbanism can help to protect or strengthen favorable climatic and micro-climate conditions in cities. A number of European cities, notably German cities, have a long history of spatial planning with climate in mind. Notable examples include Freiburg and Stuttgart, both well-known for their efforts at protecting natural air movement into and out of the city, as a way of addressing urban heat and enhancing air quality and generally the healthfulness and pleasantness of city life. Freiburg, for instance, imposes height limitations in certain zones to prevent interruption of these air flows and also designs new buildings and neighborhoods to permit better flow-through. Stuttgart, as a further example, has designated a series of "ventilation lanes" where future development is restricted [30].

Many of the biophilic city elements contained in Tables 1 and 2, will also help cities become more resilient in the face of a host of emerging resource scarcities likely in the decades ahead, including long term decline in global oil supply (peak oil), diminished supplies of potable water and food, among others. Greening cities can, as already mentioned, significantly reduce energy consumption and reduce consumption of energy for heating and cooling. In promoting modes of urban mobility other than automobiles (walking, bicycling) there is the possibility of greater resilience in the diminished oil supplies. Equally true, biophilic urbanism can achieve significant water conservation and, through the protection of peri-urban farms and agriculture and by promoting urban agriculture, might help to ensure the food security of a city.

As Figure 1 suggests, these natural features and urban biophilic qualities directly help cities to become more resilient, but also serve more indirectly to encourage healthier lifestyles and long term coping behaviors that will stand communities in good stead in the face of many future shocks and stresses. Trees and green elements at the neighborhood level, for instance, have been shown to encourage walking and outdoor-oriented activity and, in this way, create conditions for healthier individuals and families and laying a foundation for urban resilience [31].

\subsection{Biophilic Cities Can Help to Strengthen Commitments to Place}

Urban environments that are greener, more nature-full, will attract greater interest by residents and help to strengthen emotional bonds to place and community, in turn increasing urban resilience [32].

These green elements are an important aspect of place. They serve as important amenities that can strengthen distinctive place qualities, nurturing a special sense of place and, in turn, commitments to place [32,33]. When identifying those cities where there is a strong sense of the unique, that look and feel differently, elements of the natural environment are critical. Some of these, such as topography and climate, are essentially givens, that a city can do little about, but there are many ways in which through creative planning and development, connections to these elements can be strengthened, with the concomitant result that an urban citizenry may exhibit a stronger emotional connection with and care for the landscape and cityscape they call home. Furthermore, this, in turn, while a tentative 
pathway in need of additional research and evidence, may result in a host of other resilience-enhancing actions, attitudes and behaviors. Places viewed as special and distinct will likely foster emotional bonds and commitments that may in turn translate into a variety of conditions helpful to resilience (e.g., a citizenry willing to stay put and to roll up their sleeves to rebuild following a disaster or a citizenry politically engaged and participative, for instance).

A dramatic example can be seen in Austin, Texas, a city that has emphasized the cultivating of qualities that make it different or unusual (and even a buy-local campaign dubbed "Keep Austin Weird"). One of the more impressive ways that Austin has solidified its special sense of place is through the natural environment and most dramatically the way in which this city has now embraced its part-time resident population of Mexican free-tailed bats. A million and a half of these bats take up residence each spring and summer under the city's Congress Avenue bridge, and lining along the top of the bridge or sitting on blankets below the bridge to watch the nightly emergence of the bats has become a tradition in the summer and a significant tourist draw, attracting some 100,000 tourists to Austin each year. The bats deliver many ecological benefits, of course, and they bring considerable direct economic benefits to the city, but they also are part of what makes Austin different, or special, and are an important part of the unique character and feel of the city.

These biophilic qualities are an important part of what makes this city, and others, a place that Richard Florida argues is a city attractive to the so-called creative class [33]. There are thus considerable economic benefits from these biophilic programs and elements, as their distinctive place contributions serve to enhance quality of life and in turn the attractiveness of these cities. Whether cities like Austin will be able to retain businesses and residents in the face of economic stresses and downturns, and whether cultivating distinctive place qualities will deliver positive competitive advantages that might help such biophilic cities out-compete other similar cities remain open questions. However, there is considerable anecdotal evidence that cities that are greener, have more extensive green amenities, from trail systems to extensive parks to access to nature, will fare better in difficult global economic times. Furthermore, many cities have mayors and leadership teams that support improvements in biophilic conditions as an essential approach to economic development (e.g., now former mayor Richard Daley of Chicago).

Attachment and commitment to place represent significant precursors, it would seem, for taking (or being prepared to take) significant steps on behalf of a community in response to a crisis or future urban shock [34]. However, the extent to which, and precise ways in which, a unique sense of place, and personal attachments and commitments to place, will result in greater urban resilience remain open questions. A stronger commitment to place can be hypothesized to lead to a host of actions that might serve to enhance resilience and might correlate with resilience behaviors.

\subsection{Biophilic Cities Can Enhance Family and Individual Resilience and Adaptive Capacity}

Biophilic cities deliver a host of positive benefits at an individual and family level that will help to enhance ability to successfully cope with and adapt to future stressors and shocks. Nature in cities delivers considerable and often underappreciated health benefits, furthering bolstering city's capacity and ability to adapt to stresses and shocks in the future. Residents of greener neighborhoods have been found to walk more and spend more time outside, in turn with considerable positive health effects [35]. 
And in times of individual and family stress, parks, green spaces, oases of nature, become even more important. As the 2008 global economic downturn unfolded, there is evidence that urban park usage went up; nature delivers importance solace and emotional sustenance, at precisely the times when individuals and families need them [36]. A city with few such green spaces, will be less prepared, less able to provide such emotional comfort.

The evidence is compelling, as mentioned above, that the natural elements of cities-even views of trees and nature - deliver important positive impacts on mood and reduction of fatigue and, in turn, enhancing individual resilience and health. A recent study by the UK mental health organization MIND, sought to gauge the positive mood effects of a walk in nature, and found in comparison to walking in an indoor structure, the impacts were considerable indeed. At the end of these walks, participants showed marked decreases in depression, anger, tension, confusion and fatigue and increases in vigor [9].

And there are many more direct ways, of course, in which green urbanism and biophilic urban design can create more healthful environments. Planting trees and installing green rooftops and walls, permeable paving, are all strategies that provide shade and cooling through evapo-transpiration. These help to moderate urban temperatures. Trees help to ameliorate air pollution, and a robust and extensive network of storm water collection features (from permeable paving to rain gardens to urban forests) helps to reduce the problem of combined sewer overflow (CSO), a serious water quality problem that many American cities, from Seattle to Washington DC, are afflicted with.

Biophilic urbanism can help to provide the basis for healthier lives and lifestyles in many ways. An extensive network of walking and hiking trails, the close physical proximity of large blocks of greenspaces to urban neighborhoods and an urban land use pattern of nearby parks, all contribute to at the least the possibility of a more physically active, healthier lifestyle. Gardening and food production opportunities in the city provide similar benefits - the opportunity to engage in an emotionally rewarding activity, but also one with substantial calorie-burning potential and the possibility of improving diets, as well [37].

There is special concern about the unhealthy lives of children, as seen in rising child obesity rates, unhealthy diets and lack of physical activity, also little connection with outside nature. Richard Louv, in his groundbreaking book Last Child in the Woods, dubs the latter phenomenon "nature deficit disorder", pointing to many culprits of modern life, including elevated concerns about safety of outdoor environments, the overdependence on electronic media and the criminalizing of outdoor play, among others ([38]; there is a growing body of research on the importance of nature in childhood health and development, see $[39,40])$. The time spent by children on electronic media has actually increased in recent years [41], boding ill for the kinds of contact with the natural world that will foster a lifelong love of and comfort and wonder provided by nature, as well as the physical exercise and activity that outside play generates.

Biophilic cities, as Table 2 indicates, go beyond simply provision of parks and nearby nature, but seek to actively entice and induce urbanites to enjoy and participate in this nature. Cities like New York, have taken a variety of creative steps. For instance, during the summer months of July and August families can camp in city parks throughout the five boroughs. The city's Parks Department website emphasizes the fun families will have: "We start with a cookout, then a variety of evening activities, such as stargazing and night hikes. You'll sleep under the stars and awake to the birds" [42]. 
Delivering the raw ingredients of wonder and fascination in cities is a key goal of biophilic urbanism. Partly this involves re-imagining cities of abundant life and actively exploring ways that human urbanites can co-exist with other animals, from the Mexican free-tailed bats mentioned above to coyotes, birds and invertebrates, all biodiversity that cities often have in great abundance, though could do more to protect and nurture. Viewing birds (and listening to their calls) and watching other wildlife, at once provides mental and emotional connections, stress reduction and other biophysical benefits [43-45]. We find much to recommend in Jennifer Wolch's concept of "zoöpolis", arguing for the need to actively cultivate and accommodate animals in urban environments and in the process "re-enchanting" our cities [46]. Biophilic cities are cities that accommodate and celebrate other life forms and in the process help to advance resilience. Often the animals and wildlife of a city are an important contributor to a unique or distinctive sense of place [15].

Nature imparts many other affective benefits to urbanites that we are just beginning to better understand. Recent experimental evidence suggests that humans are more generous in the presence of nature [47]. Generosity and a willingness to engage in a variety of helping behaviors, are important background conditions in the event of a need to respond to and recovery from a serious natural disaster, such as an earthquake or hurricane, for instance. The sharing of critical information in the situation of an approaching storm requires a certain commitment to and concern about the welfare of others, personal qualities that may be significantly more evident in green urban environments.

Regular participation in activities that engage nature in cities can have many positive emotional and physiological benefits. Evidence is irrefutable that watching birds and wildlife can reduce stress, lower heart rates, help to calm and, in medical settings, heal us. There is much emphasis of late in the architectural community about the importance of hospital and medical facilities that integrate natural daylight, healing gardens and other features of nature, and this is a positive trend, to be sure. However, in many ways it is the larger potential of designing and planning healing cities and urban neighborhoods that is most exciting, spaces and environments that might exert considerable preventative benefits (and preventing the need to visit that hospital or cancer center later in life, it could be hoped).

Food production in cities offers opportunities to at once reconnect to landscape and nature, but also to provide some amount of food in times and circumstances where food cost and availability may be difficult. A city of gardeners, as with the experience of war time victory gardens, can produce a great deal and enhance urban resilience in the face of weather and energy shocks that may affect the flow and sourcing of food from outside a city [48]. Maintenance of economic viability of peri-urban farms and regional agriculture, as well as expanding opportunities to grow food in the leftover spaces of cities, from rooftops to re-claimed building sites, will strengthen the resilience of a city.

\subsection{Biophilic Cities Can Help Build Social Capital and Trust}

Biophilic cities and city initiatives can also, in many important ways, help to bring people together in pursuit ad enjoyment of common interests and concerns and can expand and strengthen social networks and capital. As Table 2 suggests, one way in which we can judge the biophilic bone fides of a city is by understanding the number of its citizens engaged in one or another activity centered around learning about or directly experiencing nature-watching birds, hiking and camping, participating in a variety of ecological and nature-oriented clubs and social activities. Outside activities can be solitary, 
to be sure, but they are often collective and social in nature and often result in significant friendships and social relationships.

Biophilic urbanism can also often result in the development of important new personal competencies and contribute in important ways to a sense of wellbeing and meaning. Social isolation is a significant and growing problem in northern cities and societies, and efforts centered on participation in nature - viewing and watching, interacting with, restoring and repairing — can help in significant ways to overcome that isolation.

Forests, parks and green spaces are important places for socializing and for forming new friendships. Seeland, Dubendorfer and Hansmann [39], in a study of Zurich, conclude that such green areas are important vehicles for social inclusion and for integration of immigrant youth. "Meeting and communicating in open spaces ... can be a platform for breaking up social segregation, and therefore, public places are indispensable for meeting and establishing contacts" [39]. Similar conclusions have been reached about community gardens, and such green areas integrated into living environments often serve as ready spaces for breaking-down barriers of various sorts in urban neighborhoods and providing opportunities for informal contact and socialization.

The green spaces of a city offer important sites for residents to come together and to build a degree of cohesion and trust. Furthermore, nature in the city can have important civilizing functions. Kuo and Sullivan, for example, have found that reported crime rates are lower in public housing projects with greater levels of greenery [49]. In another study of public housing residents, Sullivan and Kuo found differences in reported levels of violence and aggression depending on the presence of nearby nature: "levels of aggression and violence were significantly lower", they report, "among individuals who had some nearby nature outside their apartments than among their counterparts who lived in barren conditions" [50].

Friendships and social interaction provided by direct participation in nature activities can in turn help to strengthen adaptive capacity. Evidence of the recuperative power of friendships is growing, suggesting that a key pathway to enhanced individual and family resilience is through programs and activities that foster socialization and help build extensive and deep friendships [51,52]. Research from psychology suggests that the presence of friends will allow individuals and families to be more resilient in many ways, helping reduce perceptions of the insurmountable nature of problems and contributing to a sense that life-challenges can be overcome [52].

Biophilic green systems in cities can create the context and opportunities for people to come together. In Zurich, for example, one of the few systematic efforts to daylight streams in that city (i.e., to bring them back to the surface, from underground pipes) has created new green spaces in neighborhoods and new opportunities for kids to explore and spend time outside. There, fifteen years of work repairing and daylighting streams in urban neighborhoods has resulted in 16,000 meters of restored streams and the completion of some forty stream daylighting projects [53]. Buchli and Conraden report on the social value and benefits of these efforts [53]:

"With respect to the Cultural System, the relationship between humans and nature in urban neighborhoods and the understanding of, and care in dealing with, nature are important positive factors, which are strengthened by the open streams. The Social Systems include increased social interaction and networking in the neighborhoods, citizen participation in the planning and implementation process and interdisciplinary cooperation across the city government departments. 
Many stream opening projects have contributed to strengthening the social systems and in turn have been improved by citizen participation".

Participation and engagement with nature in cities is a key aspect of a biophilic urbanism and can take many forms. These include participation in a variety of nature clubs and organizations and activities, from bird-watching to native plant societies to fungi and food foraging. Some are more recreational (hiking clubs), while others are more educational, but all entail a form of active engagement in the community. Citizens of a biophilic city care about and are intimately engaged in experiencing and learning about nature. They (ideally) exhibit curiosity and experience fascination and wonder at the wildness and majesty in and around cities. There are a variety of social and health benefits provided through such participation and engagement. New friendships are forged, socialization and interaction fostered and additional meaning added to one's life (hopefully). Involvement in these organizations and the activities undertaken is also simply fun and delivers many of the important positive mood and restorative qualities already mentioned.

We are not the first to identify these potential connections and relationships, and Paton, Kelly and Doherty [54] have written a thorough chapter examining "natural environment as a source of adaptive capacity", with a focus on natural disasters. They suggest, among other factors, the important role that direct participation in local environment can have. "That is, there is evidence that exposure [to environment] can engender a positive and protective attitude to the local environment (e.g., Park Care, Bush Care and Land Care Groups). This exposure may come from passive or active participation in natural settings or from living in or near peri-urban areas" [54]. Many Australia cities have extensive urban Bush Care groups, a volunteer army of citizens who engage in environmental clean-up, vegetation-planting and restoration work. In the City of Brisbane alone, for example, there are more than 120 active urban bush care groups [28]. Evidence suggests then that through participation bonds with place and caring for both place and community will likely increase as a result. Paton, Kelly and Doherty summarize these potential relationships [54]:

"It is evident ... that interaction with the environment can perform a restorative function and contribute to well-being. It can also act as a protective factor in regard to mitigating present and future stress, act as a catalyst for meaningful interaction that facilitates the development and/or maintenance of adaptive capacities (e.g., self and collective efficacy) and contribute to the development and maintenance of attachment and commitment to place/community".

Engaging citizenry in a host of hands-on nature activities, then, can be an effective strategy for enhancing adaptive capacity and resilience. There are a number of exemplary programs for engaging the public in active participation on nature in cities around the world. These include master naturalists programs, which further introduce the benefits of mastery of subject. One of the best the Texas Master Naturalist program, a partnership of the Texas Parks and Wildlife Department and Texas AgriLife Extension Service. Through the program citizens receive training in the nature and natural history of the state and if they meet the requisite hours of classroom, field study and volunteer service, can become certified master naturalists. Programs like this have been wildly popular and successful on almost every measure. Some 6000 Texans have gone through the training, providing more than 1 million hours of volunteer labor since the program began in 1998 [55]. A wide range of volunteer activities has occurred through the program, from wetlands restoration, to nesting sea turtle patrol, to conducting field surveys. 
A biophilic city also places priority on educating children and young people about the nature around them and fostering these natural connections at an early stage. In Houston, Texas, for instance, a coalition of public and private entities called Houston Wilderness, has been actively educating children about the region's biodiversity and has produced a "wilderness passport" used by all fourth-grade classes in the Houston Independent School District. The passport is a guide to the region's ten ecosystems and encourages the visiting of all of them [56].

There is also growing recognition that citizens can play an essential role in helping collect data and helping in ecological sciences. This can happen through urban bio-blitzes, for instance, intensive 24-hour inventories of the biodiversity in a particular place, often within a city. Increasingly bio-blitzes, with significant citizen engagement, have occurred in a number of U.S. cities (including, for instance, one organized in Central Park, in New York City, that uncovered an entirely new species of centipede, Nannarrup hoffmani, a very small invertebrate, with 82 legs, as it turns out). Furthermore, cities can cultivate potentially life-long citizen scientists at an early stage, such as New York's effort to engage seventh graders in public and private schools throughout in monitoring salamanders at city parks [57].

City-based desert conservation efforts in the greater Phoenix area of the U.S. offer additional positive example, especially the efforts of citizens and a grassroots effort to create and manage a large desert preserve system in the City of Scottsdale. Here, amazing biophilic physical resources are available to a large segment of the population (in the form of extensive desert habitat and hiking trails, now covering more than 17,000 acres, in close proximity to neighborhoods), but are also complimented by opportunities to participate in the management of these spaces. The McDowell Sonoran Conservancy shares responsibility for operating and managing the desert preserve (along with the City of Scottsdale) and impressively has an army of 400 volunteers, who undertake minimum training and become "stewards," participating in a variety of ways in the management of, and education about, this immense reservoir of urban nature. Interestingly as budgets for parks and recreation departments all over Arizona (and the U.S.) decline, deep cuts in parks personnel have occurred. The Scottsdale model of citizen-based management reflects in many ways a more resilient approach to caring for these resources in times of severe budgetary limits.

Precisely what the long-term individual impacts of these kinds of biophilic engagement are remains to be seen and is an important area for future research. However, it stands to reason that such grass-roots involvement has many positive benefits, including a deep level of intimacy with environment and place and the cultivation of valuable friendships and social networks, among other benefits.

\section{Obstacles to Biophilic Resilience}

The power and value of biophilic urbanism as an urban resilience and sustainability strategy is clear, and a number of cities around the world have developed and are implementing ambitious programs for restoring, protecting and expanding the nature in and around them. As this paper argues, the resilience benefits are many, with biophilic investments - from trees and urban forests to healthy wetland and riparian systems - serving to expand adaptive capacity in the face of a "perfect storm" of shocks and stressors that global cities will face in the decades ahead. These will include heat waves, drought and other likely effects associated with climate change, as well as natural disasters and a host 
of potential resource shocks and scarcities, such as decline in global oil supplies and availability of water and food.

In addition to the many and considerable direct benefits from biophilic cities, there are many ways in which access to nature will make individuals, families and communities healthier and happier and will help to forge new social connections and friendships, that should make such cities more resilient. Healthier, more socially-connected individuals, families and communities will increase the likelihood of successful adaptation to this dynamic future.

But there are challenges ahead and much work still to be done. There are considerable obstacles that remain in making cities more natural and nature-full. Some of these obstacles are social and cultural, while others are economic and legal. In many cities, for instance, many examples of biophilic urban design and urbanism are prohibited or made difficult by existing codes (e.g., prohibiting the disconnecting of residential downspouts and more localized and natural forms of storm water management). Greener, more natural urban environments may be constrained by cultural and aesthetic bias-failure to see the beauty in native vegetation, for instance, or in urban landscaping other than manicured and finely mowed turfgrass, and for many urbanites, there is actually a surprising amount of fear about nearby nature that must be overcome (i.e., spiders, bats and even coyotes!).

Some resistance to a more biophilic urban realm, then, may actually come from urbanites themselves. Interestingly, new experimental research suggests that individuals underestimate the benefits and enjoyment they will receive from spending time in nature [58]. Busy schedules, heavy work commitments and over dependence on indoor-lives and car-dependent lives represent further obstacles.

And there are obstacles presented by the prevailing short-term centered political and economic decision making mechanisms. Short term economic cost may be an impediment, for instance, in installation of green neighborhood or project features, such as green walls and green roofs, though the long term savings almost always dwarfs these short term costs (and thus a need to find creative ways to encourage long term and full-cost accounting).

There are also other important ways in which cities could be biophilic that have not been explored in this paper. For instance, one notion of a biophilic city is a city that learns from, mimics and is modeled after natural systems in its functioning. Increasingly, it is recognized that a city that strives for more local and regional sourcing of material inputs, and an urban metabolism that is more circular in nature, will be more sustainable and resilient. Cities might also be viewed as more biophilic if their buildings and built environments reflect the shapes and forms of nature, attributes that may deliver important emotional and social benefits.

As this paper has pointed out in numerous places, there are still many important research and policy questions to be answered in moving cities toward biophilic urbanism. The pathways identified above are largely tentative and require much additional research and practical demonstration. We have little understanding, for instance, of what the minimum level of nature, or access to nature, is that is required by urbanites to live healthy, happy and resilient lives (and the cumulative impacts of different green features and combinations of green features, in urban environments). Much additional research is needed to better understand, moreover, the full package of resilient benefits that is provided by a biophilic cities and even the different basic ways in which urban biophilia can manifest (which will likely vary by geography and climate). 


\section{Conflict of Interest}

The author declares no conflict of interest.

\section{References}

1. Wilson, E.O. Biophilia and the conservation ethic. In Biophilia: The Human Bond with Other Species; Kellert, S., Wilson, E.O., Eds.; Harvard University Press: Cambridge, MA, USA, 1993.

2. Wilson, E.O. Biophilia; Harvard University Press: Cambridge, MA, USA, 1984.

3. Wilson, E.O. The Creation: An Appeal to Save Life on Earth; Norton and Company: New York, NY, USA, 2007.

4. Leather, P.; Pyrgas, M.; Beale, D.; Lawrence, C. Windows in the workplace: Sunlight, views, and occupational stress. Environ. Behav. 1998, 30, 739-762.

5. Herschong, L.; Roger, W.; Stacia, O. Daylighting impacts on human performance in schools. J. Illum. Eng. Soc. Summer 2002, 31, 101-114.

6. Ulrich, R. View through a window may influence recovery from surgery. Science 1984, 224, 421.

7. DeVries, S.; Verheij, R.A.; Groenewegen, P.P.; Spreeuwenberg, P. Natural environments — healthy environments? An exploratory analysis of the relationship between greenspace and health. Environ. Plan. A 2003, 35, 1717-1731.

8. Nielsen, T.S.; Hansen, K.B. Do green areas affect health? Results from a danish survey on the use of green areas and health indicators. Health Place 2007, 13, 839-850.

9. MIND. Ecotherapy: The Green Agenda for Mental Health; MIND: London, UK, 2007.

10. Van den, B.; Agnes, E.; Hartig, T.; Straats, H. Preference for nature in urbanized societies: Stress, restoration and the pursuit of sustainability. J. Soc. Issues 2007, 63, 88-89.

11. Hartig, T.; Mang, M.; Evans, G.W. Restorative effects of natural environmental experience. Environ. Behav. 1991, 33, 3-26.

12. Mitchell, R.; Popham, F. Effect of exposure to natural environment on health inequalities: An observational population study. Lancet 2008, 373, 1655-1660.

13. Atchley, R.A.; Strayer, D.L.; Atchley, P. Creativity in the wild: Improving creative reasoning through immersion in natural settings. PLoS One 2012, 7, e51474.

14. Aspinall, P.; Panagiotis, M.; Richard, C.; Jenny, R. The urban brain: Analyzing outdoor physical activity with mobile EEG. Br. J. Sport Med. 2013, doi:10.1136/bjsports-2012-091877.

15. Beatley, T. Biophilic Cities: Integrating Nature into Urban Design and Planning; Island Press: Washington, DC, USA, 2010.

16. Girling, C.; Ronald, K. Skinny Streets and Green Neighborhoods: Design for Environment and Community; Island Press: Washington, DC, USA, 2005.

17. Peter, N.; Kenworthy, J. Sustainability and Cities; Island Press: Washington, DC, USA, 1999.

18. Timothy, B.; Manning, K. The Ecology of Place; Island Press: Washington, DC, USA, 1997.

19. Peter, N.; Beatley, T.; Boyer, H. Resilient Cities: Responding to Peak Oil and Climate Change; Island Press: Washington, DC, USA, 2008.

20. Godscalk, D.R. Urban hazard mitgation: Creating resilient cities. Nat. Hazards Rev. 2003, 4, 136-143. 
21. Timothy, B. Planning for Coastal Resilience: Best Practices for Calamitous Times; Island Press: Washington, DC, USA, 2009.

22. Walker, B.; Salt, D. Resilience Thinking: Sustaining Ecosystems and People in a Changing World; Island Press: Washington, DC, USA, 2006.

23. Costanza, R.; MItsch, W.J.; Day, J.W. A new vision for New Orleans and the Mississippi Delta: Applying ecological economics and ecological engineering. Front. Ecol. Environ. 2006, 4, 465-472.

24. Costanza, R.; Pérez-Maqueo, O.; Martinez, M.L.; Sutton, P.; Anderson, S.J.; Mulder, K. The value of coastal wetlands for hurricane protection. AMBIO J. Hum. Environ. 2008, 37, 241-248.

25. US Environmental Protection Agency. Filtration Avoidance. Available online: http://www.epa.gov/region2/water/nycshed/filtad.htm/ (accessed on 7 June 2013).

26. Denver Water, Forest-to-Faucet Partnership. Available online: http://www.denverwater.org/ supplyplanning/watersupply/partnershipUSFS/ (accessed on 7 June 2013).

27. Ryerson University, 2005. Report on the Environmental Benefits and Costs of Green Roof Technology for the City of Toronto. Available online: http://www.toronto.ca/greenroofs/pdf/ fullreport103105.pdf (accessed on 7 June 2013).

28. Beatley, T.; Newman, P. Green Urbanism Down Under; Island Press: Washington, DC, USA, 2008.

29. Hazard Resistant Landscaping. Charleston, South Carolina. Available online: http://www. charlestoncounty.org/printer/www/departments/BuildingInspections/ProjectImpact/landscaping Brochure.pdf (accessed on 7 June 2013).

30. Sustainable Cities. Stuttgart: Cool City. Available online: http://www.dac.dk/en/dac-cities/ sustainable-cities-2/all-cases/green-city/stuttgart-cool-city/ (accessed on 7 June 2013).

31. Wolf, K.L. City trees, nature and physical activity: A research review. Arborist News 2008, 17, $22-24$.

32. Manzo, L.C. Towards a revisioning of emotional relationships with places. J. Environ. Psychol. 2003, 23, 47-61.

33. Florida, R. The Rise of the Creative Class; Basic Books: New York, NY, USA, 2003.

34. Manzo, L.C.; Perkins, D.D. Finding common ground: The importance of place attachment to community participation and planning. J. Plan. Lit. 2006, 20, 335-350.

35. Schantz, P.; Stigell, E. Are Green Elements Principal Pull Factors for Physical Activity; Swedish School for Sport and Health Sciences: Stockholm, Sweden, 2008.

36. Trust for Public Land. Parks and Playground Use up in Down Economy; TPL: San Francisco, CA, USA, 2009.

37. Cobb, D.T. Reclaiming Our Food; Storey Press: Adams, MA, USA, 2011.

38. Louv, R. Last Child in the Woods: Saving our Children from Nature Deficit Disorder; Algonquin Press: Chapel Hill, NC, USA, 2005.

39. Klaus, S.; Dubendorfer, S.; Hansmann, R. Making friends in Zurich's urban forests and parks: The role of public green space for social inclusion of youths from different cultures. For. Policy Econ. 2009, 11, 10-17.

40. Wells, N.; Evans, G. Nearby nature: A buffer of life stress among rural children. Environ. Behav. 2003, 35, 311-330.

41. Kaiser Family Foundation, 2010. Generation M2: Media in the Lives of 8-to-18 Year Olds. Available online: http://kff.org/other/report/generation-m2-media-in-the-lives-of-8-to-18-year-olds/ (accessed on 7 June 2013). 
42. City of New York. Family Camping. Available online: http://www.nycgovparks.org/programs/ rangers/explorer-programs\#family-camping/ (accessed on 7 June 2013).

43. Winterman, D. The Surprising Uses for Birdsong. Available online: http://www.bbc.co.uk/news/ magazine-22298779/ (accessed on 7 June 2013).

44. Godby, G. Outdoor Recreation, Health, and Wellness: Understanding and Enhancing the Relationship. Resources for the Future Discussion Paper, May. Available online: http://www.rff.org/ documents/RFF-DP-09-21.pdf (accessed on 7 June 2013).

45. Curtin, S. Wildlife tourism: The intangible, psychological benefits of human-wildlife encounters. Curr. Issues Tour. 2009, 12, 451-474.

46. Wolch, J. Zoopolis. Cap. Nat. Soc. 1996, 7, 21-47.

47. Weinstein, N.; Przybylski, A.K.; Ryan, R.M. Can nature make us more caring? Effects of immersion in nature on intrinsic aspirations and generosity? Person. Soc. Psychol. Bull. 2009, 35, 1315-1329.

48. Steel, C. Hungry City: How Food Shapes Our Lives; Random House: London, UK, 2009.

49. Kuo, F.E.; Sullivan, W.C. Environment and crime in the inner city: Does vegetation reduce crime? Environ. Behav. 2001, 33, 343-367.

50. Sullivan, W.; Kuo, F. Aggression and violence in the inner city: Effects of environment via mental fatigue. Environ. Behav. 2001, 33, 543-571.

51. Kroenke, C.H.; Kubzansky, L.D.; Schernhammer, E.S.; Holmes, M.D.; Kawachi, I. Social networks, social support, and survival after breast cancer diagnosis. J. Clin. Oncol. 2006, 24, 1105-1111.

52. Schnall, S.; Harber, K.D.; Stefanucci, J.K.; Proffitt, D.R. Social support and the perception of geographical slant. J. Exp. Soc. Psychol. 2008, 44, 1246-1255.

53. Buchli, R.; Conraden, F. The Zurich stream day-lighting program. In Enhancing Urban Environment by Environmental Upgrading and Restoration; Marsalek, J., Sztruhar, D., Urbonas, B., Eds.; Kluwer Academic Publishers: Dordrecht, The Netherlands, 2004.

54. Patton, D.; Kelly, G.; Doherty, M. Exploring the complexity of social and ecological resilience to hazards. In Disaster Resilience: An Integrated Approach; Patton, D., Johnston, D., Eds.; Charles C. Thomas: Springfield, IL, USA, 2006.

55. Texas Parks and Wildlife. Texas Master Naturalist. Available online: http://txmn.org/ (accessed on 7 June 2013).

56. Wilderness Passport: A Guide for Teachers and Scout Leaders; Houston Wilderness: Houston, TX, USA.

57. Foderado, L. Unleashing the Scientist in the Student. Available online: http://www.nytimes.com/ 2011/10/08/nyregion/salamander-study-enlists-new-york-city-seventh-graders.html?pagewanted=all \&_r $=0$ / (accessed on 7 June 2013).

58. Nisbet, E.K.; Zelenski, J.M. Underestimating nearby nature: Affective forecasting errors obscure the happy path to sustainability. Psychol. Sci. 2011, 22, 1101-1106.

(C) 2013 by the authors; licensee MDPI, Basel, Switzerland. This article is an open access article distributed under the terms and conditions of the Creative Commons Attribution license (http://creativecommons.org/licenses/by/3.0/). 